\title{
COMUNICAÇÃO E REDE AMBIENTAL: ANÁLISE DAS TICS UTILIZADAS PELO GRUPO DE PESQUISA EM GESTÃO E EDUCAÇÃO AMBIENTAL
}

Environmental Communication and Network: analysis of Information and Communication Technologies used by the Research Group on Environmental Management and Education

Comunicación ambiental y de red: análisis de las TICs utilizado por el Grupo de Investigación en Gestión Ambiental y Educación

Gabriela Stefani

Graduanda em Administração (Iniciação Científica), UNESP, Brasil gaastefani@gmail.com

Juliana Correa Bernardes Mestranda em Agronegócio e Desenvolvimento, UNESP, Brasil bernardescj@gmail.com

Cristiane Hengler Corrêa Bernardo

Professora Assistente Doutora, UNESP, Brasil cristiane@tupa.unesp.br 


\section{RESUMO}

A sociedade contemporânea e sua constante evolução vêm degradando de forma vertiginosa, os recursos naturais do planeta, tornando as questões ambientais o centro das atenções e debates. Diante deste contexto, a comunicação ambiental vinculada às tecnologias de informação e comunicação propõe o aumento da circulação de informações nesta temática, contribuindo para pesquisa e reflexões ambientais. O objetivo deste trabalho foi analisar como o acesso às TICs utilizadas pelos membros do Grupo de Pesquisa em Gestão e Educação Ambiental pode auxiliar na comunicação do grupo e disseminação de conhecimento. Utilizou-se a metodologia de estudo de caso, que investiga um fenômeno atual, dentro de um contexto de realidade e aplicou questionário semiestruturado para a coleta de dados. Concluiu-se que o acesso às TICs demonstrou ser um instrumento eficiente, efetivando informações e trocas dialógicas no ambiente virtual. Os membros do grupo entendem o conceito e a dinâmica de uma rede de educação ambiental e utilizam as redes sociais para comunicar-se entre si e para disseminar o conhecimento sobre a temática, tendo como principais meios de comunicação o e-mail, o Whats'app e o Facebook por serem meios de fácil acesso e que permitem uma rápida comunicação e interação entre o grupo.

PALAVRAS-CHAVE: Comunicação. Tecnologias de Informação e Comunicação. Rede Ambiental.

\section{ABSTRACT}

Contemporary society and its constant evolution come degrading steeply, the planet's natural resources, making environmental issues the center of attention and debate. Given this context, environmental communication linked to information and communication technologies proposes to increase the circulation of information on this subject, contributing to research and environmental considerations. The aim of this study was to analyze how access to Information and Communication Technologies used by members of the Research Group on Environmental Management and Education can help group communication and dissemination of knowledge. We used the case study methodology, which investigates a current phenomenon within a real context and applied semi-structured questionnaire to collect data. It was concluded that access to Information and Communication Technologies has proven to be an effective tool, making effective information and dialogical exchanges in the virtual environment. Group members understand the concept and the dynamics of a network of environmental education and use social networks to communicate with each other and to disseminate knowledge on the subject, the main media e-mail, Whats' app and Facebook for being a means of easy access and allow rapid communication and interaction among the group.

Key words: Communication. Information and Communication Technologies. Environmental network.

\section{RESUMEN}

La sociedad contemporánea y su evolución constante vienen degradando abruptamente, los recursos naturales del planeta, por lo que los problemas ambientales del centro de atención y debate. En este contexto, la comunicación ambiental vinculada a las tecnologías de información y comunicación propone aumentar la circulación de la información sobre este tema, lo que contribuye a la investigación y las consideraciones ambientales. El objetivo de este estudio fue analizar cómo el acceso a las TIC utilizadas por los miembros del Grupo de Investigación en Gestión Ambiental y Educación puede ayudar a la comunicación y difusión de los conocimientos grupo. Se utilizó la metodología de estudio de caso, que investiga un fenómeno actual dentro de un contexto real y aplicamos cuestionario semi-estructurado para recopilar datos. Se concluyó que el acceso a las TIC ha demostrado ser una herramienta eficaz, haciendo que la información efectiva y los intercambios dialógicos en el entorno virtual. Los miembros del grupo entienden el concepto y la dinámica de una red de educación ambiental y el uso de las redes sociales para comunicarse entre sí y para difundir los conocimientos sobre el tema, los principales medios de e-mail, Whats ' aplicación y Facebook por ser un medio de fácil acceso y permitir una rápida comunicación y la interacción entre el grupo.

Palabras clave: Comunicación. Tecnologías de Información y Comunicación. red ambiental

\section{INTRODUÇÃO}


O modo agressivo e descompromissado como o homem e sua constante evolução vem degradando os recursos naturais tornou-se alvo de debates no âmbito do ensino e das temáticas de pesquisa, os quais buscam na comunicação e nos meios de Tecnologia de Informação e Comunicação (TIC) o caminho para tentativa de defesa e conscientização da sociedade.

De acordo com Barbosa (2011), a comunicação ambiental colaborou com o aumento da circulação de informações nesta área, motivando a realização de estudos, pesquisas e reflexões ambientais.

O desafio abordado transpõe as consequências catastróficas causadas ao meio ambiente pelas produções industriais; também reflete sobre o uso extrativista da terra, o desmatamento e as diversas ações que agridem o meio e que se vive. A questão ambiental é extremamente complexa, pois apresenta inúmeras vertentes que se cruzam e demandam análises específicas (OLIVEIRA e NADER, 2007).

Diante dessas considerações e com o intuito de promover a reflexão e discussões sobre o gerenciamento e ações educativas na esfera ambiental, criou-se o grupo de Pesquisa em Gestão e Educação Ambiental, constituído no ano de 2011.

O grupo de Pesquisa em Gestão e Educação Ambiental (PGEA) é um projeto de pesquisa da Faculdade de Ciências e Engenharia da Universidade Estadual Paulista "Júlio de Mesquita Filho" (Unesp), Câmpus de Tupã, coordenado pela Profa Dra Angélica Góis Morales e compostos por profissionais de diversas áreas, assim como, pesquisadores e discentes que contribuem para uma atividade interdisciplinar voltada a responder, por meio da pesquisa, as diversas lacunas que permeiam a esfera da educação e da gestão ambiental.

O projeto trabalha nas linhas de pesquisa de Fundamentos teórico-metodológico e Formação em Educação Ambiental e Gestão.

O grupo é composto por 11 pesquisadores doutores, duas pesquisadoras mestres, cinco discentes de graduação e cinco alunos de mestrado. As reuniões do grupo ocorrem quinzenalmente, às terças feiras, das $13 \mathrm{~h} 30$ horas às $16 \mathrm{~h} 30$ horas. Durante as reuniões reflete-se sobre o processo da educação ambiental em diversos contextos, o que possibilita o intercâmbio de planejamento e execução de projetos de extensão e pesquisa.

Os membros do grupo são de vários municípios do estado de São Paulo e alguns do Paraná. A maioria conheceu o grupo por meio da Universidade nas pesquisas iniciadas já na graduação por meio da Iniciação Científica, outros por meio dos orientadores de pós-graduação e outros ainda pertencem a rede de contatos da coordenadora do programa.

A comunicação do projeto é realizada por meio de diversos instrumentos de comunicação e tecnologia, tais como: e-mail, lista de discussão, Facebook, e-mail e What'sapp. Estas redes possibilitam e mantêm a comunicação entre todos os membros do grupo, divulgam informações, promovem encontros e compartilham notícias e textos relacionados ao meio ambiente.

Diante do exposto, este ensaio apresenta a seguinte problemática: como o acesso às TICs utilizadas pelos membros do grupo de Pesquisa Gestão e Educação Ambiental auxilia na comunicação do grupo e disseminação de conhecimento nas áreas pesquisadas? 


\section{ANAP

\section{OBJETIVOS}

Objetivo Geral:

- Analisar como o acesso às TICs utilizadas pelos membros do grupo de Pesquisa Gestão e Educação Ambiental auxilia na comunicação do grupo e na disseminação de conhecimento nas áreas pesquisadas.

Objetivos Específicos:

- Verificar como o grupo compreende a Rede de Educação Ambiental;

- Descrever quais as TICs utilizadas pelos membros do grupo de pesquisa;

- Compreender qual a efetividade desses meios de comunicação no desenvolvimento do grupo e na disseminação do conhecimento.

\section{MÉTODO DE ANÁLISE}

O caminho metodológico deste ensaio apoia-se no caráter exploratório, com abordagem qualitativa, por meio de um Estudo de Caso junto aos 21 membros do Grupo de Pesquisa em Gestão e Educação Ambiental. Para tanto, utilizou-se de uma pesquisa descritiva cujos dados foram obtidos por meio de um formulário semiestruturado, aplicado pela plataforma digital Google Forms, destinado aos endereços eletrônicos - e-mail, dos participantes do grupo de pesquisa.

Sendo um estudo de caso, o formulário foi não probabilístico e a análise dos resultados dos formulários apresentou caráter descritivo, em sobreposição com o referencial bibliográfico relacionado às temáticas - comunicação, redes e educação ambiental.

A escolha do método de pesquisa justifica-se devido pelas lacunas existentes nos estudos científicos sobre os impactos da transferência de informações e tecnologias para o universo acadêmico, sobretudo, por meio digitais.

O estudo de caso único, adotado na pesquisa, caracteriza-se por ser uma análise do Grupo de Pesquisa em Gestão e Educação Ambiental, voltada para os seus membros, com o intuito de analisar a efetividade dos meios de comunicação presentes no grupo.

De acordo com Yin (2005), o estudo de caso busca esclarecer os resultados estabelecidos, tratando-se de um caso empírico, no qual se investiga um fenômeno atual, dentro de um contexto de realidade.

Dos 21 membros, 10 responderam ao questionário e como forma de manter preservada a identidade de todos, os membros serão designados neste artigo como $A 1, A 2, A 3, A 4, A 5, A 6, A 7$, A8, A9 e A10.

\section{DESENVOLVIMENTO}




\section{1. A utilização das TIC na rede ambiental}

A utilização de tecnologias para melhorar os resultados educacionais e promover a inclusão social na educação adotou duas formas principais. A primeira relaciona-se com o uso de tecnologias para gerar a inclusão social em termos de oportunidades e resultados educacionais, nas quais, as TICS foram elaboradas como meios apropriados para que os indivíduos desempenhem papéis ativos na evolução das expectativas educacionais. Já a segunda adoção, é o uso da educação para garantir a inclusão social, de modo que, as instituições educacionais e suas atividades propiciem o acesso às TICs com o intuito de fornecer capacidades informacionais necessárias (SELWIN, 2008).

A sociedade atual está relacionada intrinsicamente com os meios propiciados pelas TICs, dentre eles, as redes sociais vêm cada vez mais ganhando público e ascendendo no universo digital. De acordo com Aguiar (2007), as redes sociais podem ser definidas nas relações entre os indivíduos, que se aproximam e interagem em benefício próprio ou de um interesse em comum, público ou organização.

As redes podem ser informais (formada por círculos de amizade, família e trabalho), ou intencionais (composta por indivíduos que compartilham objetivos em comum). No caso de análise as redes são intencionais.

A internet, a partir das redes, constitui um aglomerado de usuários que se unem por meio de afinidades. Utilizam uma linguagem que mescla o texto escrito como oral, formando um novo modo de escrita, fazendo da informalidade e da rapidez suas principais características, favorecendo um estilo de comunicação própria (SCHITTINE, 2004).

Diante destas informações, compreende-se que o processo de comunicação nas plataformas virtuais, ocorre, principalmente, por meio dos diálogos entre os interlocutores, o qual, deve ser realizado sempre de forma simultânea (COSTA, 2010).

Para esta pesquisa, torna-se relevante compreender as motivações e processos de agregação para a formação de novos pesquisadores interdisciplinares, de modo a analisar quais são os fatores que possam favorecer uma melhor integração entre os integrantes da rede e proporcionar um processo de educação ambiental contínuo.

\subsection{Educação Ambiental}

Nos últimos séculos houve grandes mudanças no conhecimento humano, alterando os valores e o modo de vida da população. O surgimento do processo industrial; o constante crescimento das cidades e dos polos industriais e a consolidação do próprio sistema capitalista, sob o qual vivemos, estimulam cada vez mais o consumo em massa, aumentando a utilização dos recursos naturais da Terra e a produção de resíduos. As consequências da modernidade e do capitalismo foram aparecendo aos poucos, principalmente os problemas ambientais que têm alterado a qualidade de vida no planeta (ARAÚJO, 2015). 
O homem não se enxerga como parte do meio ambiente, não estabelece limites e muito menos critérios para a utilização dos recursos naturais, tornando constantes as agressões ao meio ambiente (CHAGAS e ANDRADE, 2014). Os efeitos da poluição ambiental são tão intensos e devastadores, que muitas vezes, a sociedade nem se dá conta de que ações corriqueiras do cotidiano, como pegar o carro e ir para o trabalho, estão contribuindo para a degradação do meio ambiente.

Como resposta a preocupação da sociedade e com a qualidade de vida, surgiu a Educação Ambiental como uma das possíveis estratégias para o enfrentamento da crise civilizatória de ordem cultural e social (SORRENTINO et al., 2005). De acordo com a Política Nacional de Educação Ambiental - Lei no 9795/1999, Art. 1ํ, a educação ambiental pode ser definida como sendo

(...) um processo de reconhecimento de valores e clarificações de conceitos, objetivando o desenvolvimento das habilidades e modificando as atitudes em relação ao meio, para entender e apreciar as inter-relações entre os seres humanos, suas culturas e seus meios biofísicos. A educação ambiental também está relacionada com a prática das tomadas de decisões e a ética que conduzem para a melhora da qualidade de vida.

A Educação Ambiental vem sendo incorporada como uma prática inovadora em diferentes âmbitos, destacando-se na sua internalização como objeto de políticas públicas de educação e de meio ambiente e sua incorporação como mediação educativa, por um amplo conjunto de práticas e desenvolvimento social (MOURA, 2001). Sua principal proposta é estimular uma cultura de interação entre natureza e sociedade, por meio da conscientização e de atitudes ecológicas nas pessoas (BRASIL, 1999).

A Educação Ambiental, cada vez mais, adota uma postura política, social e transformadora, que exige a responsabilidade e o comprometimento individual e coletivo de todos frente aos problemas ambientais (BRASIL, 2004). Além de envolver a própria vida, as questões ambientais, também envolvem a vida do planeta, colocando-se sobre ordem econômica e política, nacional e internacionalmente.

A família e a escola também devem estar aliadas para trabalhar a Educação Ambiental, uma vez que são os iniciadores da educação para preservar o ambiente natural. Embora todos os grupos sociais devam ser educados para preservar o meio ambiente, as crianças constituem um grupo prioritário, pois representam gerações futuras em formação. Como as crianças estão em fase de desenvolvimento cognitivo, supõe-se que nelas a consciência ambiental pode ser internalizada e traduzida em comportamentos de forma mais bem-sucedida do que em adultos já formados, que possuem hábitos e comportamentos de difícil reorientação (MOURA, 2001).

No entanto, para que a Educação Ambiental seja, de fato, incorporada enquanto prática, é necessário fazer o uso de instrumentos que facilitem a promoção dessa conscientização. Nessa direção, os meios de comunicação, sobretudo, as redes sociais e aplicativos de conversação podem ser de grande auxílio para essa tarefa, principalmente por terem um alto alcance de público em pouco tempo. 


\section{RESULTADOS}

As atividades promovidas pelo Grupo de Pesquisa em Gestão e Educação Ambiental fortalecem e garantem o cumprimento das suas atribuições, enquanto grupo de pesquisa, e não obstante, proporcionam uma contribuição que não se limita ao alcance dos agentes aos quais se orientam os seus objetivos e atingem todos os membros envolvidos em suas atividades.

Os relatos obtidos com a aplicação dos questionários evidenciaram a importância do conhecimento sobre redes e meio ambiente para os profissionais contemporâneos. A primeira pergunta do questionário buscava compreender o que os membros entendiam por rede de educação ambiental e no geral todos os membros responderam pertencerem a um grupo de pessoas que articulam diversas iniciativas, trocam informações e interligam pessoas que estudam a temática abordada. Vale ressaltar a resposta do membro A4, que definiu rede ambiental como "uma organização da sociedade civil ou de pesquisadores, que pode ser dedicada a promover o livre acesso à informação pública sobre o meio ambiente, a resolução de conflitos e a participação do cidadão nas questões ambientais ou promover a educação e gestão ambiental ".

Ao abordarmos os membros sobre qual (is) rede (s) de educação ambiental eles tinham conhecimento e/ou participavam, sete deles disseram que integravam a Rede de Educação Ambiental da Alta Paulista (REAP); três disseram que participam da Rede Brasileira de Educação Ambiental (REBEA) e três deles disseram que ao próprio Grupo de Pesquisa em Gestão e Educação Ambiental (PGEA).

Com o intuito de analisar a viabilidade e a influência dos meios de comunicação no desenvolvimento do PGEA, buscou-se apreender quais os meios de comunicação são utilizados pelo grupo e os citados foram o Facebook, Whats'app, e-mail, Blogger e Lista de Discussão.

Os membros relataram a facilidade de acesso aos meios citados que permitem o envio de mensagens instantâneas, propiciam a troca de informações, principalmente de imprevistos para a participação em reuniões presenciais, e por serem os meios de comunicação mais utilizados na atualidade, proporcionam uma integração entre os membros, facilitando as discussões sobre a temática. Além disso, esses meios proporcionam diversas facilidades como: baixo custo para o grupo, comunicação abrangente, imediatismo, rápida interação em perguntas e respostas, permitindo uma conexão importante para a produção e disseminação do conhecimento.

Quanto à influência desses meios no desenvolvimento do grupo e na disseminação do conhecimento os membros avaliam como importante, positiva e de fundamental relevância. De acordo com A9 esses meios servem como convocação e alerta para os membros e os leitores que acompanham as redes do grupo. No entanto, para A6 "a influência desses meios de comunicação é positiva, porém suscetível às críticas, pois muitos participantes e moderadores tornam esses meios um mero mural de informações, não interagindo, recebendo apenas a informação e não emitindo suas opiniões". 
Diferente de algumas outras redes, o PGEA não possui uma página no Facebook e por isso os membros acreditam que é preciso melhorar a utilização desse meio de comunicação, que permite a interação com outros grupos de pesquisa, tem um alto alcance e facilitaria na disseminação do conhecimento e discussões sobre a temática. O membro A8 faz uma importante colocação sobre a rede social - "a influência que o Facebook traz é alta, pois o assunto vem até a pessoa, e se ela se interessar ela vai querer se informar, diferentemente de quando não se tinha esse meio, em que as pessoas que só buscavam esse tipo de informação quando precisavam ou eram interessadas no assunto". Sem contar o modo como a essa rede social funciona, pois sempre que um "amigo" curte ou compartilha as publicações, outras pessoas terão acesso às essas informações.

\section{AGRADECIMENTO}

Agradecemos ao CNPq e a UNESP pelo apoio à pesquisa de Iniciação Científica que dá origem ao artigo.

\section{REFERÊNCIAS BIBLIOGRÁFICAS}

AGUIAR, S. (2007). Redes sociais na internet: desafios à pesquisa. Anais do XXXI Congresso Brasileiro de Ciências da Comunicação. Santos: Intercom - Sociedade Brasileira de Estudos Interdisciplinares da Comunicação.

ARAÚJO, A. R. Afinal, o que é Educação Ambiental? 2015. Disponível em:

<http://www.revistapontocom.org.br/artigos/afinal-o-que-e-educacao-ambiental> Acesso em: 22 de mar. 2015

BARBOSA, K. Por que as pessoas usam as redes sociais? 2011. Disponível em: $<$ http://super.abril.com.br/blogs/tendencias/por-que- as-pessoas- usam-as redessociais/\&gt $>$.Acesso em: 28 de mar. 2016

BRASIL. Ministério Público Federal. Política Nacional de Educação Ambiental. 1999. Disponível em: <http://pga.pgr.mpf.mp.br/boletins/arquivos-de-boletins-2009/politica-nacional-deeducacao-ambiental/?searchterm=cfm> Acesso em: 22 de mar. 2015

BRASIL. Redes: uma introdução às dinâmicas da conectividade e da auto-organização. Brasília: WWF, 2004.

CARVALHO, I. C. de M. Qual educação ambiental? Elementos para um debate sobre educação ambiental e extensão rural. Agroecol. e Desenvolvimento Rural Sustetável. Porto Alegre, v.2, n.2, abr./jun./.2001. Disponível em: <http://dev.eesc.usp.br/sustentabilidade/wpcontent/uploads/2015/01/Artigo-Carvalho2001.pdf> Acesso em: 11 de Maio de 2016.

CHAGAS, F.B.; ANDRADE, V.Z. de. Compreendendo a educação ambiental: contribuição do processo de ensino-aprendizagem de Biologia na escola. AMBIENTE \& EDUCAÇÃO 


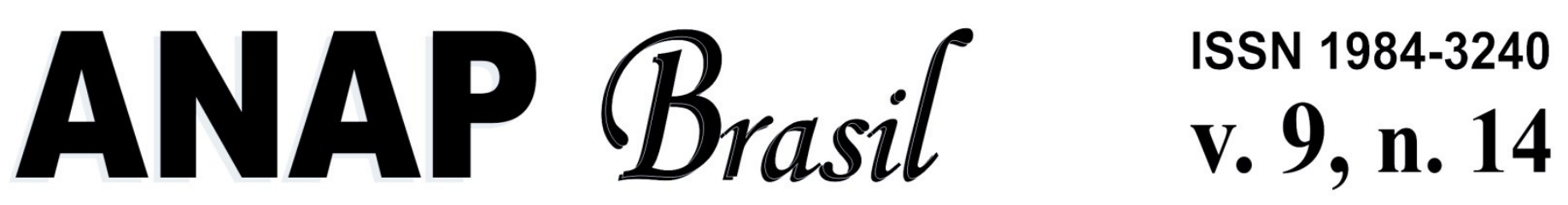

REVISTA CIENTÍFICA 2016

- Revista de Educação Ambiental, Rio Grande, v.19, p. 59-76, 02 fev. 2013. Disponível em: <http://www.seer.furg.br/ambeduc/article/view/3918/3318> Acesso em: 08 de set. de 2015

COSTA, C.O. Desafios do diálogo no relacionamento em comunidades: a experiência da Vale. In: MARCHIORI, M. (Coord.) Comunicação e Organização, reflexões, processos e práticas. São Caetano do Sul: Difusão, 2010.

OLIVEIRA, M. J. C; NADER, S. Comunicação Organizacional e Meio Ambiente: Uma análise sobre a relação entre políticas ambientais e de comunicação. 2007. Disponível em:

$<$ Http://www.abrapcorp.org.br/anais2007/trabalhos/gt2/gt2_oliveira.pdf>. Acesso em: 22 de mar. 2015.

SELWYN, Neil. O uso das TIC na educação e a promoção de inclusão social: uma perspectiva crítica do Reino Unido. Educ. Soc., Campinas, v. 29, n. 104, p. 815-850, Out. 2008. Disponível em $<$ http://www.scielo.br/scielo.php?script=sci_arttext\&pid=S010173302008000300009\&Ing=en\&nr $\mathrm{m}=\mathrm{is}>$. Acesso em maio 2016.

SCHITTINE, D. Blog: Comunicação e escrita íntima na internet. Rio de Janeiro: Civilização Brasileira, 2004. 235 p.

SORRENTINO, M et al. Educação ambiental como política pública. Educação e Pesquisa, São Paulo, v. 31, n.2, p. 285-299, maio/ago, 2005. Disponível em:

<http://www.scielo.br/pdf/ep/v31n2/a10v31n2.pdf> Acesso em: 09 de set. de 2015

YIN, R. K. Estudo de caso: planejamento e métodos. 3. ed. Porto Alegre: Bookman, 2005. 212p. 